\title{
Resilience and Change in Opera Theatres: Travelling the Edge of Tradition and Contemporaneity
}

\author{
Maria Laura Frigotto and Francesca Frigotto
}

\section{INTRODUCTION}

Resilience has recently become of great interest in various areas of social science (Fisher et al., 2018; Linnenluecke, 2017; Williams et al., 2017). Resilience refers to the ability of an individual, an organization or a system to bounce back, respond and recover when facing disturbances (Linnenluecke, 2017). According to Bartezzaghi (2013), the popularity of resilience across academic disciplines and domains of life relates to the historical moment we are facing that is characterized by the perception of a general crisis, such as psychological resilience against increasing stress,

\footnotetext{
M. L. Frigotto $(\bowtie)$

Department of Economics and Management, University of Trento, Trento, Italy e-mail: marialaura.frigotto@unitn.it

F. Frigotto

Harp Department, Conservatory of Music G.B. Martini, Bologna, Italy e-mail: francesca.frigotto@consbo.it
}

(C) The Author(s) 2022

R. Pinheiro et al. (eds.), Towards Resilient Organizations and Societies, Public Sector Organizations, https://doi.org/10.1007/978-3-030-82072-5_9 
business resilience against the financial crisis, social resilience against waves of migration.

Given the ambiguity and ignorance of the state of the environment in many realms (Frigotto \& Rossi, 2015), the hook offered by the concept of resilience is that it moves the focus from the ability to interpret the environment to the ability to resist it, ideally, independent of the source, form and manifestation of the disturbances. Resilience also reflects a trust in human abilities that is typical of contemporary, narcissistic society (Sennett, 1998). At the individual and organizational level of analysis, resilience lies in the so-called 'agency' of actors (Ruef \& Aldrich, 2006). Nevertheless, at the system level of analysis (e.g. regional systems, industries, societies, etc.), the issue of 'the agency of resilience' (i.e. who has the ability to be resilience and how much effect and intention does that actor have on the outcome) is not easily addressed (Frigotto, 2018). Thus, this chapter performs a system-level analysis of resilience to add to the debate on the agency of resilience.

The other open issue in the resilience literature concerns the role of stability and change. Resilience both enhances and emphasizes the ability of systems to resist adversities: in other words, to survive. This skill has been represented by the stability of a system's outcome (Fisher et al., 2018) or, in some cases, with the achievement of a higher level of outcome that reflects 'the ability to thrive'. However, little attention has been given to the actual change that systems experience in order to achieve stability or an increased outcome level. Resilience is related to stability as much as it is related to the change (Frigotto et al., 2022, in Chapter 1, this volume). A closer look at the relationship between stability and change provides theoretical elaboration on the resilience concept that several scholars call for (Britt et al., 2016; Duchek, 2019; Fisher et al., 2018; Kossek \& Perrigino, 2016; Linnenluecke, 2017; Vanhove et al., 2016). It also raises an important question: to what extent can an entity change in order to be considered a persisting entity and not a different entity? This is called the 'continuity of essence' in Chapter 1 and relates to the philosophical debate on essence and change originally referred to by the Greek Heraclitus (535-475 B.C.) who claimed that stability is an apparent and artificial state: given that everything is becoming, change is the only natural state.

The analysis in this chapter considers the opera as an organizational archetype (Greenwood \& Hinings, 1993, p. 1052), defined as the holistic 
system of meaning (ideas, values and beliefs) that build an interpretive scheme and the organizations that adopt and embody it. Thus, an organization archetype includes i) a system of meaning, ${ }^{1}$ ii) organisational structures (Opera Theatres or Houses $(\mathrm{OHs})^{2}$ ) and iii) artistic and working systems and practices that mirror professions and their practical knowledge (Muzio et al., 2013). We depict the evolution of the system in regard to the three dimensions mentioned above from origin to now and explore their interconnections in line with studies on the emergence, change and evolution of organizations provided by Padgett and Powell (2012) and those on organizational archetypes (Cooper et al., 1996; Greenwood \& Hinings, 1996).

This longitudinal perspective across centuries in the birth country of opera, Italy, provides the ideal empirical environment to study resilience at the system level over time. This perspective shows the connection between the agency of individuals and institutions to shed light on lowerlevel action and its nestedness into higher levels (and vice versa) for the production of the general outcome. This is relevant given that resilience can appear different according to the time, space and social scale considered (Carpenter et al., 2001; Walker et al., 2004; see also Frigotto et al., 2022 , in Chapter 1 , this volume), and it is necessary to assume a holistic perspective across levels to account for resilience as a whole. This case also allows discussion on how resilience looks over a long time span. The longitudinal view allows consideration of how much continuity is necessary to recognize resilience in the same entity. This issue links to the 'continuity of essence' as a core principle of resilience identified in Chapter 1 of this volume. The chapter is organized as follows: The next section briefly describes the debate growing in the literature around the concept of resilience and introduces the distinction between three different resilience types: absorptive, adaptive and transformative. Section three gives an overview of the literature on institutional change and organizational archetypes, providing categories and concepts that inform the understanding of the continuity of essence in resilience. Section four pertains to the research design. Section five illustrates the evolution of the opera in Italy as an organizational archetype with structure and artistic

${ }^{1}$ In this sense we will also refer to the opera as a genre of classical music consisting of a dramatic work in one or more acts set to music for singers and instrumentalists.

2 The organizations that set on stage and promote operas that typically have their headquarters in theatres designed for the performance of opera. 
professions. The last section discusses this evolution in terms of resilience outcomes.

\section{Resilience: Between Absorption, AdAPTATION AND TRANSFORMATION}

Resilience can be divided into three types that imply different changing dynamics and that vary across stability and change: absorptive resilience, adaptive resilience and transformative resilience (Frigotto, 2020; Frigotto et al., 2022, in Chapter 1, this volume).

Absorptive resilience is a form of stability of the system where change is controlled by limiting it. Here, the resilient outcome is such that change has nearly zero impact on the system (Linnenluecke, 2017). Absorptive resilience is measured in terms of return time and efficiency, where the possibility to return to the initial state is taken for granted. In this perspective, disturbances are temporary and involve 'a rather narrow range of predictable external conditions' (Holling, 1973, p. 1).

Adaptive resilience responds to unanticipated triggers that can be understood using the available knowledge. The resilience outcome reflects the achievement of a new, typically higher, performance level.

Transformative resilience responds to triggers that challenge 'sharp shifts', 'regime shifts' or 'critical transitions' and concern a variety of adversities that are typically unpredictable, unexpected or novel (Folke et al., 2010; Frigotto, 2018). Thus, resilience is measured by the effective 'persistence or probability of extinction' (Holling, 1973, p. 17) rather than the return to the former equilibrium. Transformative resilience requires a deep change of the present state while a continuity of essence is still recognizable. Despite being uncertain, it is typically associated with a higher level of performance, although it has also been linked to lower levels of performance and to high-risk survival.

As Carpenter et al. (2001) contend, resilience depends on the temporal, spatial and social scale of the observation. The latter is further divided into micro, meso and macro levels concerning, respectively, individual actors, organizations and systems. They also stress that these levels do not imply consistency with one another, and, if considered one-byone, they might render a contrasting picture of resilience at some levels. An analysis of resilience concerning these levels can only assume a holistic approach that accounts for the nestedness of smaller elements into larger 
ones and for the complexity of the micro-macro interaction (Walker et al., 2004).

\section{Archetype Change}

Organizations belonging to an archetype are subject to the same environmental demands, i.e. 'distinctive prescriptions [...] (Greenwood \& Hinings, 1996) - of the way that collective purposes should be defined and of how those collective purposes should be organized and accomplished' (Greenwood et al., 2014, p. 1214). Powell and DiMaggio (1991) outlined three pressures that induce organizations towards change: coercive (often conveyed through laws, regulations and accreditation processes), normative (grounded in the pressure to adopt shared and accepted values, standards and techniques) and mimetic (related to the need to imitate role models). These pressures refer to disturbances or adversities emerging at the level of laws, norms and behaviours, respectively. In the literature on resilience, disturbances are the triggers that require the social entity to change and show resilience (Linnenluecke, 2017).

The institutional literature has widely addressed how change occurs in institutions when pressures operate and, conversely, how change does not occur despite them. Through decoupling (Meyer \& Rowan, 1977), organizations separate the source of their legitimacy from the source of their survival, showing conformity in their windows that is not in their operations (Boxenbaum \& Johnsson, 2008, p. 80). Oliver (1991) elaborated on strategies of resistance that organizations put in place to respond to institutional processes of change, and that range from passive conformity to proactive manipulation. While the initial debate was framed in terms of transformational and incremental change (e.g. Powell \& DiMaggio, 1991; Oliver, 1991), according to Cooper et al. (1996), later, more attention was given to the variety of possibilities, between total change and total stability or inertia, by accounting for intermediate modes of change as well as for their 'evolutionary or revolutionary pacing' (Greenwood \& Hinings, 1996, p. 1023).

Cooper et al. (1996) use 'archetype transformation' and 'sedimentation' to track how organizations change from one archetype to another. Transformation refers to the case 'in which one archetype sweeps away the residues of the other' (Cooper et al., 1996, p. 625) as a reaction to dramatic change; sedimentation is when the new archetype is piled on the 
old one, and both are competing. While the first case stresses complete change, the second stresses persistence that occurs 'even when the formal structures and processes seem to change, and even when there may be incoherence' (Cooper et al., 1996, p. 624). In some sense, sedimentation describes change through the 'extension' of the archetype (Cooper et al., 1996, p. 644), meaning that change is important, but also 'unresolved' and not stabilized into a new state (Cooper et al., 1996, p. 625).

This discourse found new interest with institutional logics identifying patterns of material practices, assumptions, values, beliefs and rules that organizations take as reference for their action and cognition (e.g. the market logic or the religion logic) (Thornton \& Ocasio, 1999, p. 804; Thornton, 2004). Building on the latter, scholars considered how organizations change by adhering to more than one logic, making 'hybrid organizations' (e.g. Pache \& Santos, 2010) or by combining logics into 'hybridised logics' (Greenwood et al., 2014, p. 1217). McNulty and Ferlie (2002, p. 362) showed that even when conflicting logics trigger change, when they are too different, change does not reach completion: 'there were some pockets of change, but no organizational transformation'.

Intending to define change across the individual, organizational and system levels through networks, Padgett and Powell (2012) identified several mechanisms by which new organizational archetypes emerge as a result of 'genuine novelty' (p. 1) that, as a new ingredient at the beginning of the process, ignite new archetypes as new sprouts, as a result of adoption and diffusion or as a result of renovation. They stress the role of individual agents that, intentionally or otherwise, assume positions in networks that were previously non-connected or that benefit from their multiple roles, producing a convergence with the literature on institutional entrepreneurs (Hardy \& Maguire, 2008) and the role of agency in change. Groups of individuals with their own professional institutions also play a role in spreading change (Muzio et al., 2013).

This literature provides the language and concepts describing how change occurs and needed to discuss if that change displays resilience and of what kind. 


\section{Research Design}

This paper builds on a case study analysis used for exploratory purposes (Yin, 2009) for further development of the theory on resilience in relation to change (Siggelkow, 2007).

The case selected is the change in the opera since its foundation. Our study is longitudinal and depicts the evolution of opera as a cultural archetype, as an organizational form and as the professions of music workers, over time. For the historical evolution of opera as a cultural archetype, we relied on specialized literature in musicology. In terms of organizational form, our data include economic and financial reports, legislative debate, and the laws that were passed, as well as specific managerial literature and media reports discussing the changes in OHs. For information on artistic professions in the opera and the opera as an employer, the collection of the 30 years' experience by one of the authors, interviews with experts in the field and the contracts of musicians in opera houses over the last 50 years serve as a rich source of data. The latter reflects the need for more grounded approaches to organizational understanding (Reason \& Bradbury, 2008).

The evolution of the opera provides a good case for studying resilience at the system level because OHs' survival has been challenged several times. By the middle of the nineteenth century, there were about 200 $\mathrm{OHs}$ in Italy, and today there are $13 \mathrm{OHs}$ that belong to LyricSymphonic Foundations (LSFs) with national recognition and continuous in-house production and 29 that have local relevance as Theatres of Tradition (ToT) with very few of their own productions, mainly acting as seasonal outlets or peripheral halls for LSFs. Over the 400 years during which this drop took place, several initiatives have failed that had been previously successful. Society has changed greatly in political, economic and cultural terms, and the opera has become less interesting and less relevant to the resulting society. Since their legislative recognition, the 29 ToT have often lacked the resources for activity, while the 13 LSFs granted 'some' national funding have all gone through default procedures several times. In 2020 (time of writing), 9 of the 13 LSFs are operating under remediation procedures following an assessed default situation, paired with burning debates on the opportunity and necessity of public interventions to save them. Some of the 13 LSFs were forced to close temporarily, and their workforce were laid off and redirected to other 
professions. Eventually, the government, encouraged by public opinion, chose to intervene, saving some of the Italian OHs.

This chapter does not concern itself with resilience displayed by one or by a set of OHs, like when resilience is analysed in companies that have survived several crises over the years (such as Nokia; Duchek, 2018). In those cases, the level of analysis is the organization; in this chapter, it is the system, or 'organisational field' from an institutionalist perspective (Powell \& DiMaggio, 1991). On this matter, an analysis focusing on one organization would be limited. In fact, both legitimacy and the funding necessary to survival comes from outside the ability of an $\mathrm{OH}$ to produce income. While each $\mathrm{OH}$ is funded dependent on its choice of titles and marketing, and each $\mathrm{OH}$ will have a higher or lower level of box-office success, these elements of competition are too limited to lead to an actual differentiation or to a survival, à la Schumpeter (1934), that implies the death of some and the continuity of others because of their decisions and actions. For these reasons, we also do not draw attention to the many $\mathrm{OHs}$ that closed along the way. The question remains whether the system has changed too much to display a continuity over resilience, or, in other terms, whether it has denatured its essence such that today it has nothing to do with the Italian tradition of opera.

In terms of archetype, the opera provides a good case for studying resilience. An archetype within the neo-institutional literature is 'a set of structures and systems that reflects a single interpretive scheme and mirrors a holistic perspective that reconciles 'narrowly drawn organizational properties' under overall patterns towards which all organizations tend to converge (Greenwood \& Hinings, 1993, p. 1052). Following Cooper et al. (1996, p. 625), the opera allows the study of archetypes that are 'institutionally specific'. We stress the cultural grounds of the archetype by drawing attention to the fact that the opera is a system derived from a cultural type of communication and expression that is also a form of art or entertainment, with stylistic, aesthetic, rhetorical and communicative rules. The communicative rules are also codified and studied within musicology, and their change over time contributes to the analysis of the resilience of the system. 


\section{The Opera as an Archetype}

\section{Operatic Essence and Meaning}

The opera has survived 400 years, enduring transformations of society, taste, mores, government systems, laws and economies. In this first subsection, we address the evolution of systems of meanings that contribute to organizational archetypes in the periods of emergence and diffusion, of struggling, and of renovation and renewal.

\section{Sprouting and Spreading}

The opera was born in royal theatres as a combination of words and music called recitar cantando in the form of the serious melodrama and on minor stages in the form of comic operas and burlesque. The first public theatre was opened in Venice in 1637 for the merchant bourgeoisie, and the business model spread across the Italian peninsula. These theatres mainly performed operas during carnival time and for about one month within a series of festivals (Della Seta, 1993). Towards the end of the eighteenth century, there were about 100 theatres, which expanded to 200 by the mid-nineteenth century; basically, each city had one or more theatres that represented, even through the buildings' architecture, the social relevance of the melodrama.

The opera became the expression of the romantic period in Italy. During the Independence Wars (1848-1866), it was used to communicate and spread nationalist sentiment against the foreign sovereigns ruling the Italian territory. In particular, composer Giuseppe Verdi wrote operas such as 'The Battle of Legnano' and 'Nabucco' that represented a similar struggle and fighting attitude. As it was forbidden to propagandize nationalist thoughts, nationalists used the opera like a secret code to communicate: singing 'Va pensiero' from Nabucco became like hailing insurrection, and writing 'VIVA VERDI' on the walls of the streets was often changed into 'VIVA V.E.R.D.I', meaning long life to the king of Piedmont that should be King of Italy (Vittorio Emanuele Re D'Italia).

Towards the end of the nineteenth century, opera composers found inspiration in the novels of their contemporaries that described everyday life in the countryside (e.g. the Novels by Giovanni Verga and the Rustical Chivalry by Pietro Mascagni), real facts that occurred in the chronicles in Italy (e.g. Pagliacci by Ruggiero Leoncavallo) or fascinating new texts that were appearing in other countries, such as the discovery of West America or the colonialist relationship between the USA and Japan that 
were turned into operas by Puccini (respectively, The Girl of the Golden West and Madame Butterfly).

Operas were popular performances as they were able to speak to different levels of society, namely the new aristocrats, the bourgeois and the masses, meeting their tastes and expectations. OHs were initially funded by aristocrats and royals, then impresarios turned them into a business, renting theatres from the municipality, commissioning new operas and organising production. Such business was rarely profitable; many went bankrupt. Often the economic success of theatres was due to bundling strategies, for example, with gambling (Ernani \& Iovino, 1993).

\section{Struggling}

The opera started having trouble when it stopped being a popular expression of culture and entertainment. Two elements grounded the debate then and still ground it today: the need for financial support beyond the box-office flow and the societal value of operas. This might be independent or might progressively rely less and less on the choice of opera as entertainment.

In 1867, the Italian Parliament cancelled all support to the opera theatres and transferred the responsibility of any intervention from the state to the municipality level because of the lack of resources (Balestra \& Malaguti, 2003, p. 38). The operation of $\mathrm{OHs}$ depended on 'the mood of the councilmen' when the issue was discussed in the House (Ruggieri, 2004).

In 1885 , the music publisher Ricordi, who had commissioned many operas from famous composers, gave a speech in front of the Milan city council on the critical economic situation of the Theatre La Scala, asking for public support and arguing that the opera, as 'an Italian excellence of glorious tradition', should be publicly funded (Ernani \& Iovino, 1993, p. 7). Nevertheless, the $\mathrm{OH}$ in Genoa was closed from 1879 to 1883 , as was Bologna in 1891 and La Scala in 1897-1898 because of lack of funds. The opera was considered 'a good for an elite', especially if compared to the need to publicly fund the construction of streets, aqueducts, hospitals and schools (Balestra \& Malaguti, 2003, p. 39). In Italy, and in Milan in particular, socialist ideas spread, such as those concerning the social role of the theatre, the public utility of the arts and the public support of opera. In 1901, a referendum took place asking whether the municipality should support the costs of the La Scala. The turnout was low among the very few voters of the time, and the result was 'no' (Barigazzi, 2014). 
In terms of cultural production systems, according to musicologists, starting from the mid-1800s, OHs began evolving from 'laboratories of novelty' to museums of 'magnificent performances' of previously released operas (Rosselli, 1985). In the early days of opera, novel productions were funded by the wealthy nobles or bourgeois first, and then by the mecenate; in the last century, new operas were rare, and the opera transformed into great and magnificent reproductions, or sometimes reinterpretations, of operas, where the excellence of the performance comes from the quality of the artists and producers involved.

The framework on performance defined by Toscanini at La Scala (1920s) represents a milestone in the operatic management system and represented a model for other theatres at that time. The performance was becoming an 'event', not because of a novel opera, but because great interpreters were involved. Toscanini brought this concept to completion by adding the perfection of performance. La Scala became the apotheosis of a repertoire system where preparation was well-structured and performers were linked to the theatre, so that the previous year's productions could be reassembled with very few rehearsals. For example, over one week in 1927, the first performances of three repertoire productions and of one new production, on top of rehearsals, were staged with no lapses in the extremely high artistic standards (Sachs, 1987). Toscanini is well-known for his 'new way of working' and his 'tyrannical method' that produced a holistic performance that encompassed the aesthetic and even the moral facets of the opera. Toscanini's method incorporated the trend towards educating the public to 'consider the theatre not as something for amusement, but as something with a moral and aesthetic function that becomes part of the life of a society, part of the life of a culture' (Sachs, 1987, p. 9, quoting the words of conductor and musicologist Gianandrea Gavazzeni).

The opera is no longer the status symbol it was until probably the 1990s when, for instance, the première at La Scala was in the news for several days and fed magazines with in-depth reports on dames' expensive and excessive outfits. Opera also stopped being related to the élites, and, consequently, stopped being interesting to those who wanted to enter their circle. The amateurs also thinned out, given that the new cultural archetypes had become the popular expression in music (e.g. rock, pop, etc.). The public attended $\mathrm{OH}$ less frequently also because new technologies allowed them to reproduce music at home. In general, knowledge of the opera became less widespread, in contrast with the beginning of the 
twentieth century in which every radio station broadcasted operas and everybody still knew the repertoire and the interprets.

In the last few decades, the musical critique has also changed dramatically. By writing in the newspapers about operas and new productions being performed in $\mathrm{OHs}$, music critics informed non-experts about forthcoming productions providing context, background and the meaning of operas and production choices. For instance, during the direction of the conductor Riccardo Muti at La Scala (1986-2005), very remote operas from the past by composers such as Spontini or Cherubini were newly performed. However, they were under-appreciated by the general public, who were less and less knowledgeable on the opera and had fewer good critics to guide them. This repertoire also brought the public further in feeling the opera as something elitist and ancient that challenged the resistance even of those that had bought an expensive dress to go to the prima (in fact, in several cases, the media reported disheartened people that left the theatre after 3 or even 5 or 6 hours of opera).

\section{Re-novelling}

More recently, the opera has tried to reposition itself towards a new target, in particular, young people and tourists. The $\mathrm{OH}$ in Florence engages schools in the production of the performances, building a strong link with the local territory, or through joint-production with pop stars. A different way was explored by Fenice in Venice that addresses the tourist market with a repertoire of classics such as Traviata. This performance is repeated many times all over during the year and critics claim this endless repetition has transformed the $\mathrm{OH}$ into an 'operatic Disneyland' (The Economist, 2015 ) and transformed the opera production system (Trevisan, 2015). As a result, all $13 \mathrm{OH}$ doubled, or even more, the number of performances per year and kept the budget nearly stable.

OHs are also attempting to renew themselves within the reproduction of the tradition. Since operas can also be enjoyed by watching a performance on a screen, some OHs have pushed the renovation of the classics and on the 'feeling of the opera' that can only be appreciated live (as a representation of this feeling, think of the Julia Roberts in the movie 'Pretty woman', that is moved by compassion for Traviata and cries at her first-time performance at the opera). A recent production of Carmen in Florence in 2018, surprised the public with a totally different ending of this traditional opera. In the original libretto, Carmen is killed by her partner when she wants to break up with him but, in this new version, 
Carmen kills him for self-defence instead. The intent was to contribute to the modern discussion of violence against women. Though this new ending, the $\mathrm{OH}$ revived its previous role as a reflection on hot topics, combining the need to perform traditional, well-known operas and the need to remain relevant for society.

An interesting example of this occurred at the Arena in Verona in 2019. The American soprano, interpreting the Ethiopian princess in Verdi's Aida, refused to put on the theatrical blackface to 'appear Ethiopian', as tradition says, claiming 'I will not have my face made up in black, and it will be the first time in 106 years. It is institutionalized racism' (Manca, 2019). While this is not a debate triggered by the $\mathrm{OH}$, as in the case of Carmen, it shows that the opera is dialoguing with the present times and its debates. Finally, the opera is also picking up new themes in newly written operas. For instance, the new 'Noi due, quattro' by Elisa Fuksas shows the alienation of people that communicate mainly through mediating technologies such as mobiles and social networks and is unable to build real and face to face relationships.

\section{Operatic Organizational Structures}

The second building block of the archetype is the organizational structure. On this topic, in 1921, the La Scala Opera House was re-founded as an organization called an Autonomous Entity (AE), a legal personality under public law that owned the theatre (the building) and was in charge of organizing the activity. Resources were guaranteed by public funding, including grants from the city and the central government, as well as private funding, including individual and corporate contributions (Sachs, 1987). The attribution of regular subsidies was related to the recognition of special public interest in the opera as a form of culture and national heritage (Sicca, 1997).

Between 1929 and 1938, 11 other OHs formed AEs and were supported by municipalities and taxes on other forms of entertainment, such as radio and television subscription fees (Trezzini, 1994). In the later years, the situation of $\mathrm{OH}$ became critical several times when what they did were not in public taste and they spent more than the funding covered; the government struggled to finance $\mathrm{OH}$ s that were increasingly draining resources and displaying a 'persistent emergency state' (Ruggieri, 2004). 
In 1967, the Corona Act reformed the system by recognizing $11 \mathrm{OHs}$ and two concert institutions for a total of 13 (this set was increased in 2003 with the Opera House in Bari). This law changed the performing arts sector from 'ad hoc funding' to the regular subsidies (Sicca, 1997, p. 205) justified by the recognition of the 'relevant general interest' of the State in the OHs as 'they enable the musical, cultural and social education of the national collectivity' (Law 800/67).

In 1985, law \#163 introduced a new ad hoc fund for the performing arts granted within the Yearly Budget Act of the State; this fund was called the 'Unified Fund for Performing Arts' and was meant to give stability to the performing arts organizations by securing yearly resources (Trezzini, 1994; 2006). However, funds were distributed every year among the various organizations that produced arts; given that the plethora of applicants was variable and the resources available were unstable, the goal of this reform was limited.

A further important element defined through the AE form and the Corona Act concerned the governance of OHs. The mayor of the city in which an $\mathrm{OH}$ was located nominated the president of the $\mathrm{OH}$ while the superintendent was nominated by the Ministry of Tourism and of the Performing Arts. The superintendent was in charge of the $\mathrm{OH}$ activities, supported by the Artistic Director on the matter of artistic programming and performance responsibility. The duality in the leading roles produced ambiguity (Cori, 2004) on i) the distinctive competencies they had to have, as both sat in the board of directors, and were responsible for the artistic productions and other activities of the $\mathrm{OH}$ and ii) the responsibility and merit (or blame) that could be claimed for the $\mathrm{OH}$ performance. The result was, respectively, that i) both figures were recruited more for their political networks than their competencies and ii) each claimed for himself or attributed responsibility to the other according to the context and the advantage that could be derived with the result that no clear responsibility was identifiable (Sicca, 1997).

In 1996, the Veltroni Act 'Privatization and Managerialization' of AEs was passed after a period in which politicians contended that the state could not afford to keep funding the increasing economic and financial 'urgencies' of $\mathrm{OHs}$ given strong budgetary constraints deriving from the 'Maastricht parameters' to join the Euro.

This act ruled the mandatory transformation of AEs into organizations of private law defined as LSFs. This transformation implied two main 
changes. First, it allowed private funders to benefit from a tax deduction of $30 \%$ if they committed to give funds for at least six years. Private funders were also entitled to sit on the Board of Directors with the State, the Region and the Municipality if they contributed with a fund that was no less than $12 \%$ of the total funds for at least six years. Second, it introduced an accounting and reporting system akin to that of private organizations that was more oriented to result and performance.

The act took until 2000 to become operational because the Constitutional Court had to rule on its constitutionality, putting OHs in three years of limbo. The Bassanini Act (2001) overcame this impasse by transforming by law the OHs into LSFs and by stating the public nature of $\mathrm{OH}$ despite the private legal form.

The objectives of the Veltroni Act were, essentially, not achieved, and OHs faced increasing continuous crises. Between 2005 and 2010, five of the 14 LSFs almost defaulted, and the Ministry took charge through 'special commissioners' (Ferri, 2016). Private contributions never reached the hoped-for percentages, and later amendments to the Act reduced the private participation quota to $5 \%$ of state funding for at least 2 years (instead of 3).

Towards the end of 2013, the Bray Act was passed. It was meant to respond to the needs of the many LSFs facing deep financial and economic crises and to the reducing resources and the OHs' inability to manage them. It established a strict minimum performance standard, identified in both the economic and financial structural equilibrium, to be reached within three years and to be met by all $\mathrm{OHs}$ in default conditions that wanted to access the 'special fund' that represented the only way to avoid closure. The standard was intended to delineate between survival and closure. The request to benefit from the 'special fund' implied the willingness of the LSF to revise scheduled artistic programmes and implement downsizing and salary reduction if necessary. LSFs that did not meet the standards were at first said to be destined to compulsory administrative winding up and later (Act \# 175/2017) to lose the status of LSF and exit its public funding and control system to become Lyric Symphonic Theatres with a lower level of public support. Lay-offs and salary decreases occurred, and later laws moved the deadline from December 2016 to December 2018 (Act \# 160/2016) and then to December 2019 (Act \# $205 / 2017$ ) and reduced the requirements, asking for a yearly economic equilibrium and a tangential rather than structural equilibrium of assets 
and liabilities. The actual implementation of the Bray Act by the established deadlines would have required implementing decrees that should have occurred at least six months before the deadline, but this never came to fruition. This communicated to LSFs that the cut-off promised by law was not going to be pursued as it was written.

During these changes, the opera as an organization experienced adversities from different sides that challenged the idea that they should receive public funding. The ambiguity in the public nature of the opera and the uncertainty in the actual provision of yearly funding were at the heart of these continuous adversities. Respectively, the $13 \mathrm{OHs}$ risked default. They faced complete shut down a few times, the last in 2014, but remain to this day.

The objectives behind the transformation into LSFs were not achieved, and the LSFs found themselves facing a growing crisis; between 2005 and 2010, five foundations defaulted, though they did not close. After the reform, which led to overcoming the old lyrical institution based on public interest, private contributions should have been the norm, but they rarely reached the percentage necessary for achieving balance. The numerous changes to the legislative decree n. 367/1996 that occurred between 1998 and 2010, such as a further lowering of the participation rate of private individuals to $8 \%$ of state funding for at least 2 years (instead of 3 ), are only 'buffering measures' to solve specific and contingent problems, and did not substantially and incisively affect the institutional set-up, the production structure or the financing mechanisms. They did, however, change the OHs dramatically, as they oriented more to their sustainability than to their excellence, making a musician more akin to an assembly line worker than an artist.

\section{Operatic Professionalism: From Amateurs to Professional Artists}

The third building block of the archetype analysed here concerns rules, practices and behaviours. These often converge into professions that are involved in archetypes (Muzio et al., 2013). The generation of AE stabilized the production of operas over the years. While the laws addressed all the institutions that organized an operatic season of more than one month, in those theatres that were more active for longer periods, the operatic season was extended throughout the year. Moreover, artistic work was pushed from dilettantism to professionalism, as it could be performed during the whole year, producing a significant increase in 
quality. In the $\mathrm{AE}$, the superintendent had authority over hiring artists or workers and the president had the power to refuse. The president, as already said, was also the mayor and the main contributor to the $\mathrm{OH}$. In this legislative framework, the OHs in Rome, Florence and Milan worked for the financial stabilization of their artists.

Between 1934 and 1938, two kinds of institutions related to $\mathrm{OHs}$ were founded: governmental institutions that controlled the decisions and operations of $\mathrm{OH}$ under the Ministry of Popular Culture and governmental institutions that protected workers in theatres through unions (Balestra \& Malaguti, 2003, p. 42). The union of performing arts workers provided general improvement of the working conditions and salary, but it also transformed the approach of performing arts workers towards the public, government and the $\mathrm{OH}$ itself. According to Pestalozza (1981) during fascism, musicians developed a strong parasitic and patronizing approach towards the state, exploiting the fact that the state wanted to secure their intellectual support and offered corporate-union assistance and an organization that allowed them to benefit from the welfare state. The influence of this framework continued after this period. For example, Nicola De Pirro played a primary role in the definition and leadership of the OHs, remaining in the governmental General Management of Performing Arts until 1963 (Balestra \& Malaguti, 2003).

In the 1920s, Toscanini was the first to conceive of the orchestra musician as a professional as we understand it today. As mentioned earlier, his pursuit of performance excellence implied the professionalism of artists as natural (Sachs, 1987). However, the fact that many OHs worked through 'seasons' of half a year or shorter, with interruptions between them (Della Seta, 1993), led to the need for many artists to have jobs for the 'quieter periods'. Well-known anecdotes are shared by artists and musicologists on the matter. In the 1920s, Maestro Gui, hunting for orchestra musicians, was told that in a nearby city there was a good trombone player in the café by the sea in Viareggio (interview with Music Critic and Artistic Director, Daniele Spini, Firenze, 26/09/2019). Similarly, in the choir in the Arena di Verona in 1950, one of the tenors was the local barber that used to sing arias out loud while doing his 'other job', and altos were school teachers and hairdressers (interviews with experts in Verona, 2015-2016).

When the artist of the opera was allowed to focus on a single profession, the quality of performances greatly increased. The technical level required to qualify for a short-list today was not even considered possible 30 years ago. For the trumpet, for instance, the mastery of the 'double 
staccato' is a basic technical element for a professional player today, but was considered nearly impossible in 1960. Higher education for artists was done in conservatories for musicians, singers and composers and, since 1971, in universities for other aspects of the performing arts (DAMS at Bologna University). Until the Mascagni Act in the mid-1980s, instructors in the conservatories also worked in $\mathrm{OHs}$, so competencies for performing in $\mathrm{OHs}$ were acquired in regular education. After the Mascagni Act, instructors had to opt for either the conservator or the $\mathrm{OH}$, leading to a lack of orchestral competencies and practical knowledge of new artists. The effect was fewer young artists qualifying for operatic jobs. Instead, they were given temporary positions with little pay that did not include rest days over a production and began a few days after the start of the rehearsals scheduled for a production. Indeed, this also impacted the quality of the performance.

In social terms, the profession of the artist in the $\mathrm{OH}$ was respected, at least until the 1990s. It provided prestige, recognition and paid well. Later, a growing discussion on the budget for performing arts and culture puts $\mathrm{OHs}$ in a bad light, framing $\mathrm{OH}$ workers as parasitic, living on others' ability to produce wealth. In addition, especially in technical professions, OHs, like other fields in the cultural sector, were often used politically as a social buffer to unemployment, with positions in excess of what was required. For the same political reason, $\mathrm{OH}$ workers have typically shown a rigid attitude towards change and negotiation and have always claimed their contractual rights. For instance, they obtained some integrative 'allowances for humidity' or 'for black tie', acknowledging the special conditions of their work. In addition, strikes in $\mathrm{OHs}$ were not unusual. Since 2014, with the Bray Act, salaries have dropped and many allowances have been cancelled. Altogether, the social perception of the $\mathrm{OH}$ profession has changed dramatically (interviews with Orchestra professionals, 2016-2018).

\section{Discussion}

In this chapter, the literature on resilience was related to the literature on change in institutions, and, more precisely, in organizational archetypes. This provides the first contribution to both streams of literature, as it establishes a link that supports cross-fertilization. Resilience was analysed through the evolution of the opera and, as a further contribution to resilience analysis, presented a picture of resilience that accounts 
for the main components of an archetype: symbolic meanings, organizational structures, professional knowledge and behaviours building a social system that includes aesthetic, economic, legislative and sociological aspects (Greenwood \& Hinings, 1993).

From a longitudinal perspective, we showed that the opera experienced coercive, normative and mimetic pressures in relation to disturbances that triggered change. Laws during the nineteenth century that directed the opera towards educational or cultural aims, and later to managerialization, introduced coercive disturbances. The role of first-in-class played by La Scala functioned both as a source of normative and mimetic pressure. Over time, the opera evolved from being a popular expression, to elitist, to entertaining and to an educational form of culture, and from a public system to a managerialized one where efficiency is the target. This evolution shows the contours of a plurality of institutional logics (Kraatz \& Block, 2008; Thornton, 2004) pertaining to the opera. In the early days, the opera reflected the logic of amusement and entertainment that supported a market or business logic when it was a popular form of divertissement. Then, it responded to a logic of exhibitionism related to the need for nobles to show off their status and power when it became the main expression of nobles and their courts. Recently, it has included the logic of business that assumes there is a market for opera, especially for opera reproductions of ancient cultural expressions; the logic of culture, conceiving opera as a system of meaning that can still speak to contemporary society and the logic of opera professions, supporting the idea that the opera contains artistic excellence and performance can be cultivated by artists.

This chapter also addresses the extent to which we can talk of resilience when deep change occurs (Frigotto et al., 2022, in Chapter 1, this volume) and when a long time scale is considered (Carpenter et al., 2001). Our analysis showed that the opera went through transformative resilience, as it was challenged in its survival and identity several times since its birth. The opera has changed dramatically since its early days, so much that we hardly understand the operatic works of the early days when they are performed (e.g. Muti's choices of openings at La Scala). Several directions of transformation are visible, ranging from the disneyfication (fitting with a box-office/business logic) to the componentization of opera's pieces, including the change of ending and of performing traditions (fitting with a logic of contemporary cultural relevance). Moreover, intense transformation was introduced by legislation towards determined 
managerialization and strict attention to costs and revenues in line with the broader introduction of new public management in all areas of public organizations since the 1990s and that triggered the opera to lean towards the private organization model. To the resilience discourse, the most important question concerns the continuity of essence in this evolution, or, in other terms, if these pressures and conflicting institutional logics have transformed the nature and identity of opera or if it is possible to recognize a red thread across these changes.

Political assessments of the need for change in the opera have typically resulted in new laws and new nominations to the top roles in OHs. However, our analysis showed that, despite the intent of the legislation, and compared to the intent and determination of specific actors (e.g. impresarios or Toscanini) that acted as institutional entrepreneurs producing and spreading change (Battilana et al., 2009; Hardy \& Maguire, 2008) or organizations within the system (e.g. La Scala) or other institutions (e.g. fascism and its political propaganda), agency played a limited role in the evolution of the opera and, therefore, on resilience. For example, the objective pursued with the transformation to LSFs was not achieved, nor was the 2013 Bray Act able to push OHs towards efficiency and business logic. This is witnessed by the fact that the deadlines in the Bray Act that foresaw the closing down of $\mathrm{OH}$ had to be postponed several times. Similarly, the traditional operatic repertoire was not abandoned nor exclusively and slavishly reproduced for box-office logic.

In our interpretation, this means two things. First, that a holistic perspective on change is necessary, one that considers the various actors and logics involved and puts them in perspective for an integrated understanding of the overall outcome that might not reflect the actors' intentions nor their design. This requires rich data and different competencies for a multifaceted understanding of actors and logics. In this case, organization studies, musicology and music practice were necessary, which are the areas of expertise of the authors. This also implies that change derives from the interplay between the micro, meso and macro levels and that one level considered in isolation cannot account for change, similar to the relevance of the social scale in the observation of resilience (Carpenter et al., 2001).

Second, the opera as an archetype has gone through a transformative kind of resilience and is still transforming but has not abandoned its original nature of cultural and entertaining artistic expression that 
combines reflection with amusement. The latter has been 'reproduced as in chemistry' (Padgett \& Powell, 2012) through the staging of traditional operas with renewed interpretations, endings and social reflections. In the eyes of some, the latter is the essence of opera that should be treated as the line of continuity that is preserved and along which resilience is observed. Others instead think that the opera can only survive through new cultural tastes and little funding by becoming keener to adapt to contemporary entertainment. Several music critics have envisioned the denaturing of opera in the future, given that, in several aspects, it has been heading towards a business-driven factory rather than a cultural organization. The co-existence of these different logics may make the opera a hybrid organization (Pache \& Santos, 2010). Further, the opera maps onto different organizational archetypes that also co-occur and whose competition has not been solved; this situation configures archetype sedimentation (Cooper et al., 1996). The transformation itself, described as 'sweeping away' the residues of previous archetypes (Cooper et al., 1996, p. 625), has not taken place, given that the tension between logics and the decoupling of $\mathrm{OHs}$ and the various pressures are still taking place. change is still ongoing and only future studies will be able to analyse the whole evolution when opera reaches its final destination.

Acknowledgements The Authors wish to thank Giuseppe Bargiacchi, Giorgio Brunetti, Cristiano Chiarot, Pierangelo Conte, Maria di Freda, Luigi Maria Sicca, Daniele Spini, Enrico Sciarra, Alberto Triola, Giovanni Verona, Luca Zan, and all the Artists we interviewed, for sharing and discussing with us their views on the evolution of the opera and of its meaning, structure and professions. All the mistakes and omissions remain our own.

\section{REFERENCES}

Balestra, C., \& Malaguti, A. (2003). Organizzare musica. Legislazione, produzione, distribuzione, gestione nel sistema italiano. Franco Angeli.

Barigazzi, G. (2014). La Scala racconta. Hoepli.

Bartezzaghi, S. (2013, January 23). L'età della resilienza. La Repubblica. Retrieved October 2, 2021 from https://ricerca.repubblica.it/repubblica/arc hivio/repubblica/2013/01/23/leta-della-resilienza.html

Battilana, J., Leca, B., \& Boxenbaum, E. (2009). How Actors change institutions: Towards a theory of institutional entrepreneurship. The Academy of Management Annals, 3(1), 65-107. 
Boxenbaum, E., \& Jonsson, S. (2008). Isomorphism, diffusion and decoupling. In R. Greenwood, C. Oliver, K. Sahlin, \& R. Suddaby (Eds.), The SAGE handbook of organizational institutionalism (pp. 78-98). SAGE Publications.

Britt, T. W., Shen, W., Sinclair, R. R., Grossman, M. R., \& Klieger, D. M. (2016). How much do we really know about employee resilience? Industrial and Organizational Psychology, 9(2), 378-404.

Carpenter, S., Walker, B., Anderies, J. M., \& Abel, N. (2001). From metaphor to measurement: resilience of what to what? Ecosystems, 4(8), 765-781.

Cooper, D. J., Hinings, B., Greenwood, R., Brown, J. L., Cooper, D. J., Hinings, B., ... Brown, J. L. (1996). Sedimentation and transformation in organizational change: The case of canadian law firms. Organization Studies, 17(4), 623-647.

Cori, E. (2004). Aspetti istituzionali e dinamiche organizzative nel teatro d'opera in Italia. FrancoAngeli.

Della Seta, F. (1993). L'organizzazione dei teatri e le condizioni del musicista, in Italia e Francia nell'Ottocento. EDT.

Duchek, S. (2018). Entrepreneurial resilience: A biographical analysis of successful entrepreneurs. International Entrepreneurship and Management Journal, 14(2), 429-455.

Duchek, S. (2019). Organizational resilience: A capability-based conceptualization. Business Research, 13(1), 215-246.

The Economist. (2015). Give the tourists what they want (March 24). Online at: https://www.economist.com/prospero/2015/03/24/giving-thetourists-what-they-want

Ernani, F., \& Iovino, R. (1993). La Repubblica degli enti lirici-sinfonici. Problemi e prospettive del teatro d'opera in Italia (1967-1992). EDT.

Ferri, P. (2016). I commissariamenti nel settore culturale italiano: obiettivi, azioni, risultati. Editoriale scientifica.

Fisher, D. M., Ragsdale, J. M., \& Fisher, E. C. S. (2018). The importance of definitional and temporal issues in the study of resilience. Applied Psychology, $68(4), 583-620$.

Folke, C., Carpenter, S. R., Walker, B., Scheffer, M., Chapin, T., \& Rockström, J. (2010). Resilience thinking: integrating resilience, adaptability and transformability. Ecology and Society, 15(4), 20.

Frigotto, M. L. (2018). Understanding novelty in organizations: A research path across agency and consequences. Palgrave Macmillan.

Frigotto, M. L. (2020). Reframing resilience on novelty and change. In E. Powley, B. Caza \& A. Caza (Eds.), Research handbook on organizational resilience, (pp. 53-69). Emerald Group Publishing Limited.

Frigotto, M. L., \& Rossi, A. (2015). An explanatory coherence model of decision making in ill-structured problems. Mind \& Society, 14(1), 35-55. 
Frigotto, M. L., Young, M., \& Pinheiro, R. (2022). Resilience in organizations and societies: The state of the art and three organizing principles for moving forward. In R. Pinheiro, L. Frigotto, \& M. Young (Eds.), Towards resilient organizations and societies: A cross-sectoral and multi-disciplinary perspective (pp. 3-45). Palgrave.

Greenwood, R., \& Hinings, C. (1993). Understanding strategic change: The contribution of archetypes. Academy of Management Journal, 36(5), 10521081.

Greenwood, R., \& Hinings, C. R. (1996). Understanding radical organizational change: Bringing together the old and the new institutionalism. Academy of Management Review, 21(4), 1022-1054.

Greenwood, R., Hinings, C. R., \& Whetten, D. (2014). Rethinking institutions and organizations. Journal of Management Studies, 51, 1206-1220.

Hardy, C., \& Maguire, S. (2008). Institutional entrepreneurship. The Sage bandbook of organizational institutionalism, 1, 198-217. London: Sage.

Holling, C. S. (1973). Resilience and stability of ecological systems. Annual Review of Ecology and Systematics, 4(1), 1-23.

Kossek, E. E., \& Perrigino, M. B. (2016). Resilience: A review using a grounded integrated occupational approach. The Academy of Management Annals, 10(1), 729-797.

Kraatz, M. S., \& Block, E. S. (2008). Organizational implications of institutional pluralism. The Sage handbook of organizational institutionalism (Vol. 840, pp. 243-275). Sage.

Linnenluecke, M. K. (2017). Resilience in business and management research: A review of influential publications and a research agenda. International Journal of Management Reviews, 19(1), 4-30.

Manca, B. (2019). Tamara Wilson, il soprano protesta contro l'Aida all'Arena di Verona: "Non mi farò truccare il volto di nero, è razzismo istituzionalizzato" Il Fatto Quotidiano. 27 Luglio. Retrieved October 2, 2021 from https:// www.ilfattoquotidiano.it/2019/07/27/tamara-wilson-il-soprano-protestacontro-laida-allarena-di-verona-non-mi-faro-truccare-il-volto-di-nero-e-raz zismo-istituzionalizzato/5352769/

McNulty, T., \& Ferlie, E. (2002). Process transformation?: A case of reengineering in health care. Oxford University Press.

Meyer, J. W., \& Rowan, B. (1977). Institutionalized organizations: Formal structure as myth and ceremony. American Journal of Sociology, 83(2), 340-363.

Muzio, D., Brock, D. M., \& Suddaby, R. (2013). Professions and institutional change: Towards an institutionalist sociology of the professions. Journal of Management Studies, 50(5), 699-721.

Oliver, C. (1991). Strategic responses to institutional processes. Academy of Management Review, 16(1), 145-179. 
Pache, A.-C., \& Santos, F. (2010). When worlds collide: The internal dynamics of organizational responses to conflicting institutional demands. Academy of Management Review, 35, 455-476.

Padgett, J. F., \& Powell, W. W. (2012). The emergence of organizations and markets. Princeton University Press.

Pestalozza, L. (1981). Lo Stato dell'organizzazione Musicale: La Svolta Del Fascismo e La Sua Lunga Durata. Musica-Realtà, II/5 (Agosto 1991), 143-160.

Powell, W. W., \& DiMaggio, P. J. (1991). The new institutionalism in organizational analysis. University of Chicago Press.

Reason, P., \& Bradbury, H. (2008). The Sage handbook of action research: Participative inquiry and practice. Sage.

Rosselli, J. (1985). L'impresario d'opera. EDT.

Ruef, M., \& Aldrich, H. (2006). Organizations evolving. Sage.

Ruggieri, M. (2004). Il teatro lirico tra pubblico e privato (1898-2001). Economia Della Cultura, Numero Speciale, 1, 39-98.

Sachs, H. (1987). Arturo Toscanini dal 1915 al 1946. EDT.

Schumpeter, J. A. (1934). The theory of economic development; an inquiry into profits, capital, credit, interest, and the business cycle. Harvard University Press.

Sennett, R. (1998). The corrosion of character: The personal consequences of work in the new capitalism. WW Norton \& Company.

Sicca, L. M. (1997). The management of opera houses: The Italian experience of the Enti Autonomi. International Journal of Cultural Policy, 4(1), 201-224.

Siggelkow, N. (2007). Persuasion with case studies. Academy of Management Journal, 50(1), 20-24.

Thornton, P. H. (2004). Markets from culture: Institutional logics and organizational decisions in higher education publishing. Stanford University Press.

Thornton, P. H., \& Ocasio, W. (1999). Institutional logics and the historical contingency of power in organizations: Executive succession in the higher education publishing industry, 1958-1990. American Journal of Sociology, 105(3), 801-843.

Trevisan, P. (2015). Reshaping Opera. A Critical Reflection on Arts Management. Ph.D. Dissertation, Ph.D. Program in Management, Ca' Foscari University in Venice.

Trezzini, L. (1994). Il quadro di riferimento dello spettacolo dal vivo in Bodo C. (a cura di), Rapporto sull'economia della cultura in Italia, 1980-1990, Presidenza del Consiglio dei Ministri, Dipartimento per l'informazione e l'editoria, Roma.

Trezzini, L. (2006). Dalle prime normative al Fondo unico per lo spettacolo. Economia Della Cultura, 16(1), 7-14.

Vanhove, A. J., Herian, M. N., Perez, A. L. U., Harms, P. D., \& Lester, P. B. (2016). Can resilience be developed at work? A meta-analytic review 
of resilience-building programme effectiveness. Journal of Occupational and Organizational Psychology, 89(2), 278-307.

Walker, B., Holling, C. S., Carpenter, S. R., \& Kinzig, A. (2004). Resilience, adaptability and transformability in social-ecological systems. Ecology and Society, 9(2), 1-9.

Williams, T. A., Gruber, D. A., Sutcliffe, K. M., Shepherd, D. A., \& Zhao, E. Y. (2017). Organizational response to adversity: Fusing crisis management and resilience research streams. Academy of Management Annals, 11(2), 733-769.

Yin, R. (2009). Case study research design and methods. Sage.

Open Access This chapter is licensed under the terms of the Creative Commons Attribution 4.0 International License (http://creativecommons.org/licenses/ by $/ 4.0 /$ ), which permits use, sharing, adaptation, distribution and reproduction in any medium or format, as long as you give appropriate credit to the original author(s) and the source, provide a link to the Creative Commons license and indicate if changes were made.

The images or other third party material in this chapter are included in the chapter's Creative Commons license, unless indicated otherwise in a credit line to the material. If material is not included in the chapter's Creative Commons license and your intended use is not permitted by statutory regulation or exceeds the permitted use, you will need to obtain permission directly from the copyright holder.

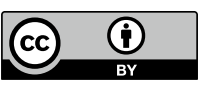

